Research Article

\title{
A Study of Cerebrospinal Fluid Examination using Urine Reagent Strips for Diagnosis of Meningitis
}

\author{
Archana Buch', Disha Gupta 2 , Bhavana Vasu 3 , Hetal Rathod ${ }^{4}$ \\ 1,2,3,4Dr. D.Y. Patil Medical College, Hospital and Research Center, Dr. D.Y. Patil Vidyapeeth, Pune. \\ DOI: https://doi.org/10.24321/2454.8642.201919
}

\section{I $\quad \mathbf{N} \quad \mathbf{F} \quad \mathbf{O}$}

\section{Corresponding Author:}

Archana Buch, Dr. D.Y. Patil Medical College, Hospital and Research Center, Dr. D.Y. Patil Vidyapeeth, Pune.

E-mail Id:

drarchanabuch@yahoo.co.in

Orcid Id:

https://orcid.org/0000-0002-8251-1941

How to cite this article:

Buch A, Gupta D, Vasu B, Rathod H. A Study of Cerebrospinal Fluid Examination using Urine Reagent Strips for Diagnosis of Meningitis. Rec Adv Path Lab Med 2019; 5(4): 1-6.

Date of Submission: 2019-11-30

Date of Acceptance: 2020-01-21
$\begin{array}{llllllll}\mathbf{A} & \mathbf{B} & \mathbf{S} & \mathbf{T} & \mathbf{R} & \mathbf{A} & \mathbf{C} & \mathbf{T}\end{array}$

Background: Diagnosis of suspected meningitis is still a problem in rural areas where sound laboratory setups are not available. An early recognition of meningitis and its timely interventions can help to cure the disease. The urine reagent strips may help in evaluation of Cerebrospinal Fluid (CSF) leukocytes, proteins and glucose. Our aim was to study the role of urine reagent strip for rapid diagnosis of meningitis.

Methods: This was prospective single-blinded study conducted on 50 CSF samples of suspected cases of meningitis. The samples were subjected to routine standard CSF examination and index text using urine reagent strips for semi quantitative analysis of CSF leucocytes, proteins and glucose. The diagnostic accuracy of the reagent strip for different cutoff levels was estimated and tabulated in the form of sensitivity, specificity, positive predictive value and negative predictive value. Medcalc software was used for statistical analysis.

Result: The sensitivity and specificity for leucocytes using strip method were $26 \%$ and $100 \%$ respectively, for the proteins $56 \%$ and $85 \%$ respectively and for glucose, it was $88 \%$ and $73 \%$ respectively. The accuracy for leucocytes, proteins and glucose were $72 \%, 72 \%$ and $84 \%$ respectively.

Conclusions: The urinary strips have limited use in the bedside diagnosis of meningitis.

Keywords: Cerebrospinal Fluid, Meningitis, Urine Reagent Strips, Leucocytes

\section{Introduction}

Meningitis is an infection of the membranes and fluid that cover brain and spinal cord. It is more prevalent in rural areas and in lower socio-economic groups. It is a medical emergency which requires prompt recognition and treatment. Its early diagnosis and treatment are essential for prevention of neurological deficits and death. ${ }^{1,2}$

In our country Neonatal Meningitis is one of the most prevalent causes of neonatal deaths. According to NCBI report Neonatal Mortality is 20 per 1000 live births. ${ }^{3}$

Diagnosis of meningitis requires estimation of protein, glucose and leucocyte count in CSF. ${ }^{2}$ These tests cannot be performed without the availability of reasonably sound laboratories and experienced medical laboratory scientists. The time required for transport of sample to laboratory and processing of sample may cause undue delay in the diagnosis and management. ${ }^{4}$ 
Urine Reagent Strips are available in the market. These strips are used for urine analysis for determining leucocyte count, proteins and glucose. We intend to find out the utility of urine reagent strips in identification of leucocyte count, proteins and glucose of CSF and to determine its accuracy, sensitivity and specificity when compared with standard techniques used for CSF examination. If this is proved statistically accurate, it can be used as a rapid bedside test for early detection of meningitis even in remote health care centers.

\section{Materials and Methods}

We have conducted a prospective single blinded study on 50 consecutive CSF samples received in our laboratory at Dr. D. Y. Patil Medical College and Research Center, Pune. Institute Ethics Committee clearance was obtained.

Study Duration: Two months.

\section{Selection Criteria}

- Inclusion Criteria: CSF samples received in our laboratory within an hour of tap.

- Exclusion Criteria: CSF sample with Hemorrhagic taps.

CSF samples were obtained with all aseptic measures using the standard operating procedure of lumbar puncture. The instrument used was a sterile lumbar puncture needle. The CSF samples were collected in sterile plain bulbs as follows: Tube 1 for chemistry (glucose and protein) and serology. Tube 2 for hematology (total cell count and differential count). All the CSF samples collected were subjected to Index and Definitive tests.

\section{Definitive Test}

These tests were performed by independent blind observer. Standard methods were used for estimation of leucocytes, proteins and glucose as described below:

Leucocyte Count: Total leucocyte count was done by Microscopic Method using Fuchs -Rosenthal chamber. In this method the CSF was diluted using the Turk's solution. Coverslip was placed on the counting chamber and the fluid was charged. It was allowed to stand for 2 minutes and then cells were counted using ' $\mathrm{L}$ ' rule on Neubauer's chamber under the microscope. ${ }^{5}$

For differential cell count, the CSF sample was centrifuged at a high speed for 10 minutes and a smear was made from the sediment. After staining it with Romanowsky stain, the smear was examined under the microscope to look for neutrophils and lymphocytes. Normal CSF should contain $<5$ lymphocytes $/ \mathrm{mm}^{3}$.

Protein Analysis: Proteins were analyzed on fully automated SIEMENS Dimension in our laboratory. In the reaction sequence, pyrogallol red combines with sodium molybdate to form a red complex with maximum absorbance at 470 $\mathrm{nm}$. The protein in the sample reacts with this complex in acid solution to form a bluish - purple colored complex, which absorbs at $600 \mathrm{~nm}$. The absorbance at $600 \mathrm{~nm}$ is directly proportional to the concentration of protein in the sample. Normal CSF protein levels in adults is $15-45 \mathrm{mg} / \mathrm{dL}$.

Glucose Estimation: It was also done by fully automated Siemens Dimension present in our laboratory. Hexokinase catalyzes the phosphorylation of glucose to glucose-6phosphate by ATP. Glucose-6-phosphate dehydrogenase oxidizes glucose-6-phosphate in presence of NADP to gluconate-6-phosphate. No other carbohydrate is oxidized. The rate of NADP formation during the reaction is directly proportional to the glucose concentration and is measured photo metrically. Normal CSF glucose ranges from 45 - 80 $\mathrm{mg} / \mathrm{dL}$. Any alterations in the normal range of the CSF leucocytes, proteins and glucose will result in meningitis. ${ }^{5}$

\section{Index Test}

This test was performed by using urinary reagent strips in order to determine protein, glucose and leucocyte count in CSF. The strips were of Laura M brand and manufactured by ERBA LACHEMA. For index test, 2-3 drops of undiluted CSF were added to patches of leucocytes esterase, proteins and glucose. The test area present on the strip contains polyionic polymer bound to hydrogen ion. On its reaction with cations present in urine, $\mathrm{H}$ ions are released causing color change. The color change was recorded and interpreted using the manufacturer-provided color grading.

The reagent strip is designed to detect the range of leukocytes from 15 to 500 cells $/ \mathrm{mm}^{3}$.

Depending on the color obtained after dipping the strip in CSF sample they are graded as negative for cell count of $0-10$ cells $/ \mathrm{mm}^{3},+1$ for $10-25$ cells $/ \mathrm{mm}^{3},+2$ for $25-75$ cells/ $\mathrm{mm}^{3}$ and +3 for $75-500$ cells $/ \mathrm{mm}^{3}$.

In case of protein, the interpretation of the colors on the reagent strips ranges as negative for $<30 \mathrm{mg} / \mathrm{dL}$, trace for $30 \mathrm{mg} / \mathrm{dL},+1$ for $30-100 \mathrm{mg} / \mathrm{dL},+2$ for $100-500 \mathrm{mg} / \mathrm{dL}$ and +3 for $500-1000 \mathrm{mg} / \mathrm{dL}$. So, it was decided whether the protein was $<30$ (normal), $30-100 \mathrm{mg} / \mathrm{dL},>100 \mathrm{mg} / \mathrm{dL}$ based on color change.

In case of glucose, the interpretation of the colors on the reagent strips ranges as negative for $<50 \mathrm{mg} / \mathrm{dL}$, trace for $50-100 \mathrm{mg} / \mathrm{dL},+1$ for $100-300 \mathrm{mg} / \mathrm{dL},+2$ for $300-1000 \mathrm{mg} /$ $\mathrm{dL}$ and +3 for $>1000 \mathrm{mg} / \mathrm{dL}$. So, it was decided whether the glucose was $<50$ (normal), $50-100 \mathrm{mg} / \mathrm{dL}$ or $>100 \mathrm{mg} / \mathrm{dL}$ based on color change. In meningitis, glucose levels are reduced, hence for statistical analysis negative and trace values were considered to be indicative of disease process.

\section{Statistical Analysis}

Medcalc software was used for statistical analysis.

The diagnostic accuracy between reagent strip method and standard test were tabulated under the following headings: 
Sensitivity (SN): [True Positive/ (True Positive + False Negative)] x 100

Specificity (SP): [True Negative/ (True Negative + False Positive)] $\times 100$

Positive Predictive Value (PPV): [True Positive/ (True Positive + False Positive)] x 100

Negative Predictive Value (NPV): [True Negative/ (True Negative + False Nagative)] $\times 100$

Accuracy: [(True Positive + True Negative)/ (True Positive + True Negative + False Positive + False Negative)]

\section{Result}

The study was conducted on 50 consecutive CSF samples. There was a fair distribution of male $(52 \%)$ and female (48\%). Among these, $24 \%(n=12)$ cases were in the pediatric age group, out of which $6 \%(n=3)$ were neonates. The adult cases participated in this study were $76 \%(n=38)$.

The results obtained from the urine reagent strip test for three cardinal parameters - leucocyte, protein and glucose were compared with those of reference standard. The sensitivity and specificity for the leucocytes using urine strip method were $26 \%$ and $100 \%$ respectively. The accuracy was $72 \%$.
Similarly, the sensitivity and specificity for the proteins using the index test were $56 \%$ and $85 \%$ respectively. The accuracy was $72 \%$. The sensitivity and specificity for glucose were $88 \%$ and $73 \%$, respectively. The accuracy was $84 \%$ which is higher than the other two parameters.

In our study, we observed moderate diagnostic accuracy of the three cardinal parameters - leucocytes, proteins and glucose as $72 \%, 72 \%$ and $84 \%$, respectively when performed on 50 samples only (Table 1 ).

The specificity is high in leucocytes so it is easy to identify and confirm the true negatives. For identification of proteins in CSF using Urine strips, the specificity is good which helps in identifying the true negatives. So true negatives help in ruling out meningitis. In glucose, sensitivity is better than specificity hence true positives are identified which indicates patient could have meningitis. The combined interpretation of cell count, protein and glucose in the background of detailed clinical history and examination may help in provisional diagnosis of meningitis as a bed side test using Urine strip for CSF examination.

We have additionally observed that the specificity of each parameter was increased with the increase in the values of cell counts, proteins and glucose (Figure 1). This is useful in ruling out meningitis in doubtful cases.

Table I.Diagnostic accuracy of urine reagent strips

\begin{tabular}{|c|c|c|c|c|c|c|c|c|c|}
\hline Index Test & $\begin{array}{c}\text { True } \\
\text { Positive } \\
\text { (TP) }\end{array}$ & $\begin{array}{c}\text { False } \\
\text { Positive } \\
\text { (FP) }\end{array}$ & $\begin{array}{c}\text { False } \\
\text { Negative } \\
\text { (FN) }\end{array}$ & $\begin{array}{c}\text { True } \\
\text { Negative } \\
\text { (TN) }\end{array}$ & $\begin{array}{c}\text { Sensitivity } \\
\text { (SN) }\end{array}$ & $\begin{array}{c}\text { Specificity } \\
\text { (SP) }\end{array}$ & PPV & NPV & Accuracy \\
\hline Leucocyte & 5 & 0 & 14 & 31 & $26 \%$ & $100 \%$ & $100 \%$ & $68 \%$ & $72 \%$ \\
\hline Protein & 13 & 4 & 10 & 23 & $56 \%$ & $85 \%$ & $76 \%$ & $69 \%$ & $72 \%$ \\
\hline Glucose & 31 & 4 & 4 & 11 & $88 \%$ & $73 \%$ & $88 \%$ & $73 \%$ & $84 \%$ \\
\hline
\end{tabular}

PPV - Positive Predictive Value; NPV- Negative Predictive Value.

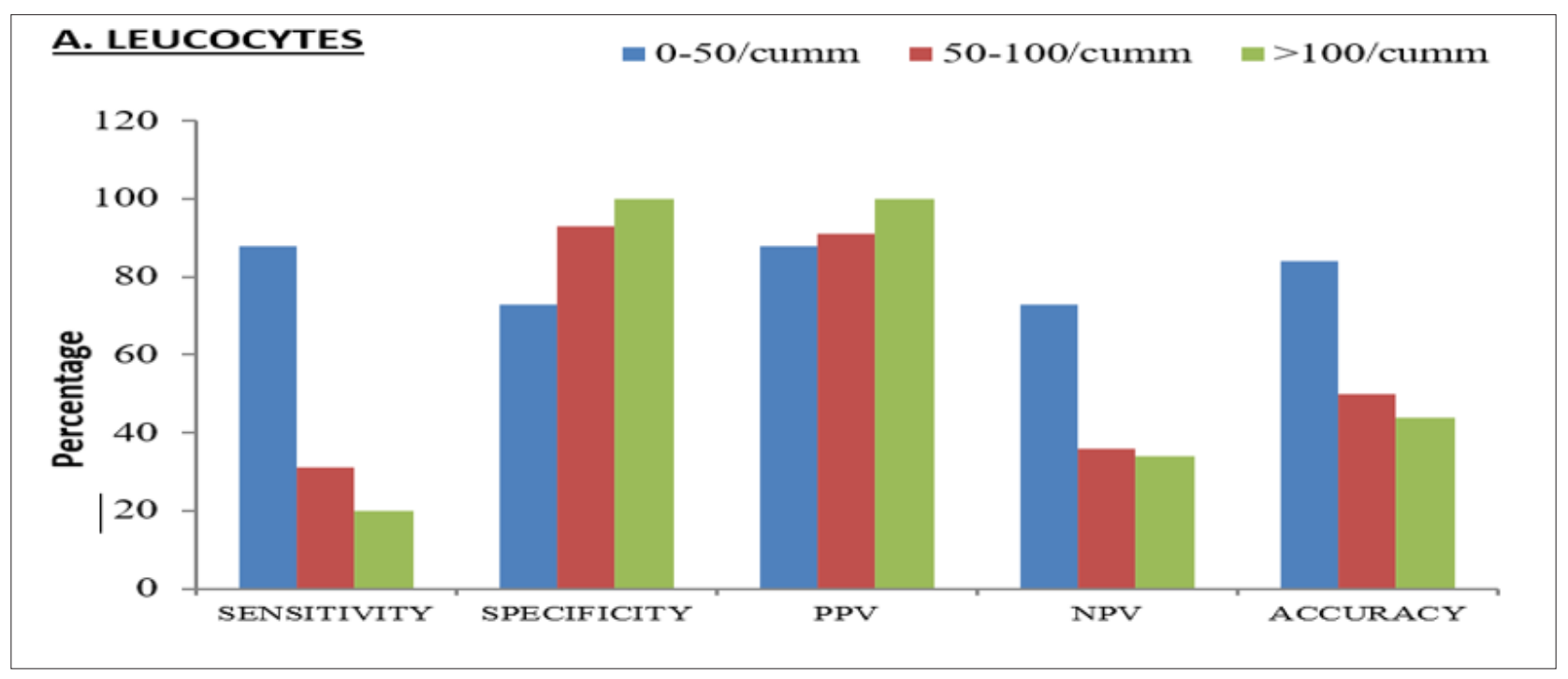



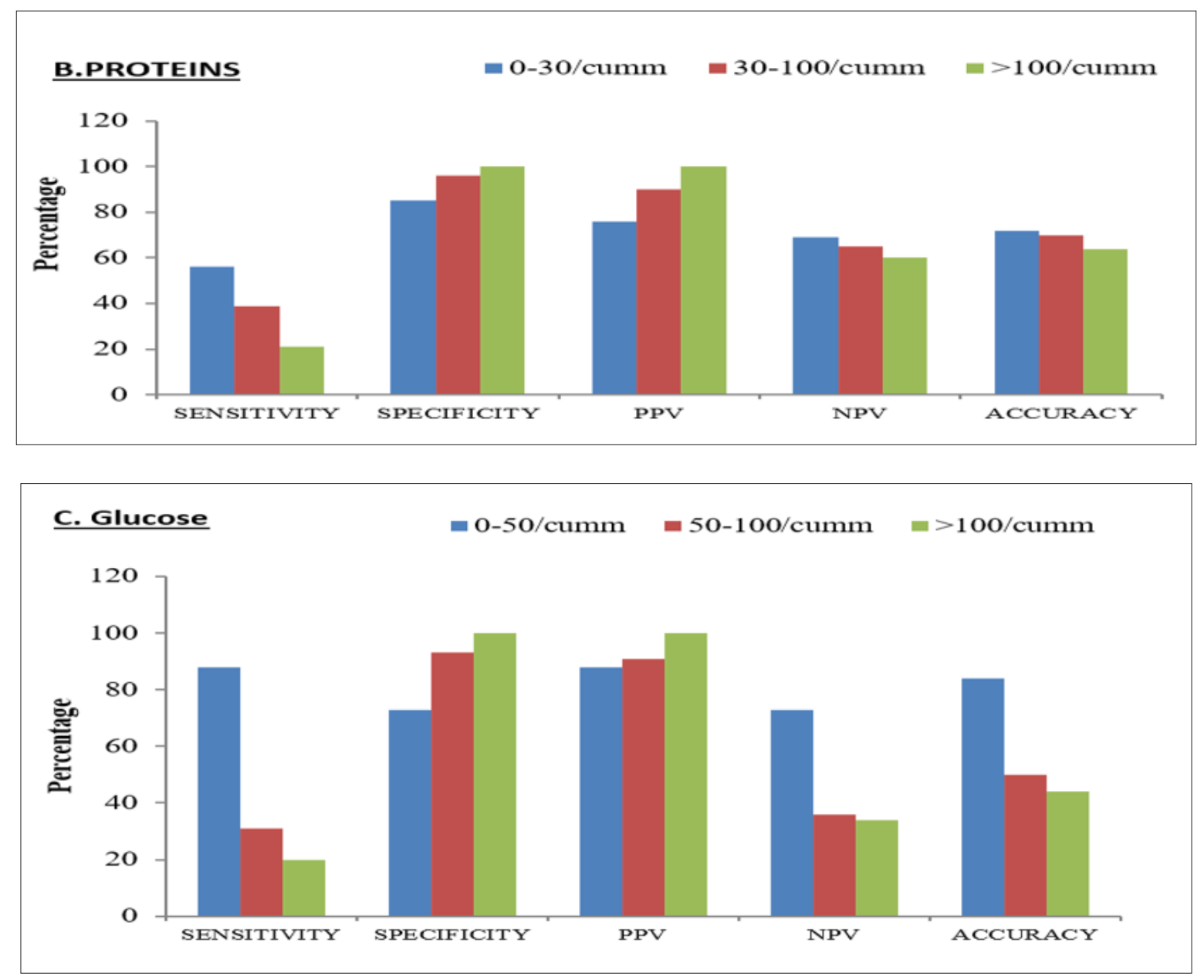

Figure I.Diagnostic accuracy of urinary reagent strips for $(A)$ leucocytes (B) proteins and (C) glucose

Table 2.Comparison of parameters obtained in different studies

\begin{tabular}{|c|c|c|c|c|c|c|c|c|c|}
\hline \multirow{2}{*}{ Name } & \multirow{2}{*}{ Sample size } & \multirow{2}{*}{ Strips } & \multicolumn{2}{|c|}{ Leucocyte } & \multicolumn{2}{|c|}{ Proteins } & \multicolumn{2}{|c|}{ Glucose } & \multirow{2}{*}{ Reference } \\
\cline { 4 - 10 } & & & SN\% & SP\% & SN\% & SP\% & SN\% & SP\% & 11 \\
\hline Mazumder S et al. $^{11}$ & 100 & - & 89.2 & 98.6 & 85.7 & 95.6 & 71 & 100 & 11 \\
\hline Chikkannaiah P et al. $^{4}$ & 103 & Combur -10 & 96.6 & 94.5 & 94.9 & 45.8 & 76 & 86 & 4 \\
\hline Joshi D et al. $^{12}$ & 75 & Combur-10 & 85.2 & 89.6 & 98.1 & 57.1 & 61 & 96 & 12 \\
\hline Gupta A et al. $^{13}$ & 360 & $\begin{array}{c}\text { Combur } 10 \text { (roche } \\
\text { diagnostics) }\end{array}$ & 100 & 96 & 92 & 98 & 99 & 54 & 13 \\
\hline Present study & 50 & Laura M & 26 & 100 & 56 & 85 & 88 & 73 & \\
\hline
\end{tabular}

\section{Discussion}

Meningitis is characterized by inflammation of the leptomeninges. It is associated with high mortality and psychoneurological sequelae due to damage of the neurological structure. ${ }^{6}$ Any delay in the treatment of meningitis in neonates can cause significant morbidity in future such as impairment of vision, hearing problems along with motor, cognition and behavioral problems. ${ }^{7,8}$ It is very imperative to start the treatment within 3 hours in order to reduce the morbidity and mortality. ${ }^{9}$ The diagnosis greatly depends on the estimation of leucocytes, protein and glucose present in the CSF. ${ }^{10}$

Urine reagent strip was used by S. Mazumder et al. for estimation of CSF leucocytes, proteins and glucose. His study revealed sensitivity of $89.2 \%$ and specificity of $98.6 \%$ for leucocyte. Proteins showed sensitivity of $85.7 \%$ and specificity of $95.6 \%$. Glucose showed sensitivity of $71.42 \%$ and specificity of $100 \% .^{11}$ 
Several other studies are performed in the past. The statistical analysis of these studies revealing sensitivity, specificity and accuracy of urine strips in diagnosis of meningitis are shown in the Table 2.

If leucocyte count is negative by urine strip it will definitely rule out the disease. Protein results by urine strips showed low sensitivity and good specificity, hence based on these results one can rule out meningitis if proteins are negative. Glucose results on the other hand will help in identifying true positive cases when glucose tests show negative and trace results. We found increased sensitivity for low glucose level. This can be of diagnostic utility in pyogenic meningitis where low glucose is detected in CSF due to utilization of glucose by bacteria. This may point towards early detection of bacterial meningitis in the patient.

Though, we have additionally observed that the specificity of each parameter was increased with the increase in the values of cell counts, proteins and glucose (Figure 1). This is useful in ruling out meningitis in doubtful cases.

However, our study showed a limited use in the bedside diagnosis of meningitis due to moderate diagnostic accuracy and relatively less sensitivity for detection of proteins and sugar. Our study revealed very low sensitivity for cell count.

The reason for these results could be low sample size, Reagent strip by different Manufacture and due to some unknown preanalytical error.

\section{Conclusion}

We conclude that urine reagent strips have limited use in diagnosing Meningitis. It can be used only as a screening test for provisional diagnosis but cannot be used for definitive diagnosis.

\section{Limitation and Future Scope}

This was a short-term pilot project carried out within a short span of two months duration with sample size of 50. Larger study with good manufacturer reagent strip, also comparing reagent strips of different manufacturer in same sample can be taken up as a future scope of research in this field.

\section{Financial Support and Sponsorship}

The study has been conducted after approving the student project (Reference ID: 2019-08551) from ICMR, New Delhi in 2018. The support and sponsorship of ICMR is duly acknowledged.

\section{Conflicts of Interest: None.}

\section{References}

1. Kumar A, Debata PK, Ranjan A, Gaind R. The role and reliability of rapid bedside diagnostic test in early diagnosis and treatment of bacterial meningitis. Indian J Pediatr 2015; 82(4): 311-314. Available from: https://
link.springer.com/article/10.1007\%2Fs12098-0141357-z [PubMed/ Google Scholar].

2. Scarborough M, Thwaites GE. The diagnosis and management of acute bacterial meningitis in resourcepoor settings. Lancet Neurol 2008; 7(7): 637-648. Available from: https://www.thelancet.com/journals/ laneur/article/PIIS1474-4422(08)70139-X/fulltext [PubMed/ Google Scholar].

3. Polin RA, Harris MC. Neonatal bacterial meningitis. Semin Neonatol 2001; 6(2): 157-172. Available from: https://www.sfnmjournal.com/article/S10842756(01)90045-4/pdf [PubMed/ Google Scholar].

4. Chikkannaiah P, Benachinmardi KK, Srinivasamurthy V. Semi-quantitative analysis of cerebrospinal fluid chemistry and cellularity using urinary reagent strip: an aid to rapid diagnosis of meningitis. Neurol India 2016; 64(1): 50-55. Available from: http://www. neurologyindia.com/article.asp?issn=0028-3886; yea $r=2016$; volume $=64$; issue $=1$; spage $=50$; epage $=55$; aula $\mathrm{st}=$ Chikkannaiah [PubMed/ Google Scholar].

5. Kawthalkar S. Essentials of Clinical Pathology. JP Medical Ltd, India. 2018; 97-98.

6. Ray P, Badarou-Acossi G, Viallon A, Boutoille D, Arthaud $M$, Trystram D et al. Accuracy of the cerebrospinal fluid results to differentiate bacterial form non bacterial meningitis, in case of negative gram-stained smear. Am J Emerg Med 2007; 25(2): 179-184. Available from: https://www.ajemjournal.com/article/S07356757(06)00376-7/fulltext [PubMed/ Google Scholar].

7. De Louvois J, Halket S, Harvey D. Effect of meningitis in infancy on school-leaving examination results. Arch Dis Child 2007; 92(11): 959-962. Available from: https:// adc.bmj.com/content/92/11/959.full [PubMed/ Google Scholar].

8. Krebs VL, Costa GA. Clinical outcome of neonatal bacterial meningitis according to birth weight. Arq Neuropsiquiatr 2007; 65(4B): 1149-1153. Available from: http://www.scielo.br/scielo.php?pid=S0004282X2007000700011\&script=sci_arttext [PubMed/ Google Scholar].

9. Brancusi F, Farrar J, Heemskerk D. Tuberculous meningitis in adults: A review of a decade of developments focusing on prognostic factors for outcome. Future Microbiol 2012; 7(9): 1101-1116. Available from: https://www. futuremedicine.com/doi/pdfplus/10.2217/fmb.12.86 [PubMed/ Google Scholar].

10. Chaudhuri A, Martinez-Martin P, Kennedy PG, Andrew Seaton R, Portegies P, Bojar M et al. EFNS guideline on the management of community-acquired bacterial meningitis: Report of an EFNS task force on acute bacterial meningitis in older children and adults. Eur J Neurol 2008; 15(7): 649-659. Available from: https:// onlinelibrary.wiley.com/doi/full/10.1111/j.1468- 
1331.2008.02193.x [PubMed/ Google Scholar].

11. Mazumder S, Ramya BS, Biligi S. Utility of urine reagent strips in cerebrospinal fluid analysis: An aid to bedside diagnosis of meningitis. Ind J Path Microbiol 2018; 61(3): 356-359. Available from: http://www.ijpmonline. org/article.asp?issn=0377-4929; year=2018; volume= 61;issue=3;spage=356; epage=359; ;ulast=Mazumder [PubMed/ Google Scholar].

12. Joshi D, Kundana K, Puranik A, Joshi R. Diagnostic accuracy of urinary reagent strip to determine cerebrospinal fluid chemistry and cellularity. J Neurosci Rural Pract 2013; 4(2): 140-145. Available from: https:// www.thieme-connect.com/products/ejournals/ pdf/10.4103/0976-3147.112737.pdf [PubMed/ Google Scholar].

13. Gupta A, Dwivedi T. Reagent strips test: A simplified methods for prompt analysis of cerebrospinal fluid in neurological disorders in emergency. Pract Lab Med 2019; e00124. Available from: https:// www.sciencedirect.com/science/article/pii/ S2352551718301082 [PubMed/ Google Scholar]. 